\title{
Coronavirus Disease 2019_-The Changing Face of Dentistry
}

\author{
Abid S Khan ${ }^{1}$, Pallavi Madanshetty ${ }^{2}$, Smita Musani ${ }^{3}$, Taufique Shaikh ${ }^{4}$
}

\begin{abstract}
Constant risk of contact and proximity to oral cavity and the production of aerosol have increased the risk of coronavirus disease 2019 (COVID-19) among dentists. Transmission of coronavirus (CoV) is through respiratory droplets, close contact, or aerosols. Coronaviruses are lipid bilayer enveloped viruses with the viral structure formed primarily of structural proteins having affinity toward the angiotensin-converting enzyme 2 receptors, which are found abundantly on the mucosa of tongue. These facts have led to categorization of dentistry as a very high exposure risk job with high potential for exposure to COVID-19. Due to the absence of vaccine till date, it is crucial to scrutinize and refine preventive maneuver and to implement strict and efficient infection control protocols to prevent cross infection of COVID-19 among dentists, dental team, and patients in the clinical setup. Based on the existing guidelines and the recently initiated guidelines from the Centers for Disease Control and Prevention and World Health Organization, this study provides infection control strategies in the field of dentistry in general and in prosthodontics in particular. Keywords: Aerosols, COVID-19, Dentistry, Disinfection, Personal protective equipment, Severe acute respiratory syndrome coronavirus-2. International Journal of Prosthodontics and Restorative Dentistry (2020): 10.5005/jp-journals-10019-1267
\end{abstract}

\section{INTRODUCTION}

The end of 2019 was marked by a pneumonia outbreak in Wuhan, China, with an unknown etiology. ${ }^{1}$ The infectious agent of this viral pneumonia was later identified as the seventh member of the family of coronaviruses (CoVs) that infect human and was temporarily named as novel coronavirus (2019-nCoV). ${ }^{2-4}$ The naming of viruses is based on their genetic structure to facilitate the development of diagnostic tests, vaccines, and medicines which is done by the International Committee on Taxonomy of Viruses (ICTV). On February 11, 2020, ICTV announced "severe acute respiratory syndrome coronavirus-2 (SARS-CoV-2)" as the name of the new virus and the World Health Organization (WHO) announced "coronavirus disease 2019 (COVID-19)" as the name of the disease caused by this virus. It was given this name because the virus is genetically related to the CoV that is responsible for the SARS outbreak in 2003. Although related, both the viruses are different. ${ }^{5}$

In the past two decades, a zoonotic virus, SARS-CoV-2, is the third CoV cross species to infect human population (with probable origin from bats or another host). ${ }^{6}$ The other two zoonotic viruses were severe acute respiratory syndrome coronavirus caused by SARS-CoV in 2002 and Middle East respiratory syndrome coronavirus caused by MERS-CoV in 2012. ${ }^{7}$ Coronavirus disease (COVID-19) crisis was declared as "Public Health Emergency of International Concern" by WHO, on January 31, 2020, ${ }^{1}$ since there was an international spread of disease and it potentially required a coordinated international response.

\section{MORPHOLOGY OF SARS-CoV-2}

Severe acute respiratory syndrome coronavirus- 2 is a spherical positive single-stranded RNA virus. It is characterized by spike proteins projecting from the virion surface. ${ }^{8,9}$ The spherical morphology of virus along with the spike projections on it led to the name coronavirus from the Latin word corona meaning crown. The virus under an electron microscope appears as a royal crown, hence the name corona. ${ }^{8,9}$ Coronaviruses are lipid bilayer enveloped viruses with the viral structure formed primarily of structural proteins, such as spike (S-protein), membrane, envelope,
1,3,4 Department of Prosthodontics, MA Rangoonwala College of Dental Sciences and Research Centre, Pune, Maharashtra, India

${ }^{2}$ Department of Prosthodontics, Rural Dental College, Pravara Medical Trust, Pravara Institute of Medical Sciences, Loni, Maharashtra, India

Corresponding Author: Abid S Khan, Department of Prosthodontics, MA Rangoonwala College of Dental Sciences and Research Centre, Pune, Maharashtra, India, Phone: +91 9860671696, e-mail: abid. skhan@yahoo.com

How to cite this article: Khan A, Madanshetty P, Musani S, et al. Coronavirus Disease 2019-The Changing Face of Dentistry. Int J Prosthodont Restor Dent 2020;10(2):77-82.

Source of support: Nil

Conflict of interest: None

and nucleocapsid proteins, and hemagglutinin-esterase protein in some beta CoVs. ${ }^{10}$

\section{Relationship between Viral Pathogenicity OF SARS-COV-2 AND SARS-COV}

Common cold in human adults and children is a significant symptom caused by a group of viruses known as CoVs. ${ }^{6}$ Severe acute respiratory syndrome caused by SARS-CoV has a unique pathogenesis of causing both upper and lower respiratory tract infections. ${ }^{6,11}$ The $89 \%$ genome sequence of SARS-CoV-2 resembled to bat SARS-like-CoVZXC21 and $82 \%$ of its genome sequence resembled to human SARS-CoV. The cell entry receptor, angiotensin-converting enzyme 2 (ACE2), for SARS-CoV-2 to infect human is same as that of SARS-CoV. 6,11,12 The S-protein has high affinity to ACE2 receptor leading to rapid spread of the SARS-CoV-2 similar to SARS-CoV. The finding of ACE2 as the receptor of SARSCoV-2 also indicates that human organs with high ACE2 expression level are potentially the target of SARS-CoV-2. ${ }^{13}$ Notably, ACE2, the receptor protein of both SARS-CoV and SARS-CoV-2, is abundantly present in the epithelia of the lung and small intestine of humans, and hence CoVs can infect the lower respiratory and gastrointestinal tract of mammals. ${ }^{14}$ Expression of ACE2 is higher on the mucosa of 
tongue in oral cavity, indicating that the oral cavity can be a highrisk transmitter of SARS-CoV-2. ${ }^{15}$ Symptoms in this disease usually begin with fever, dry cough, fatigue, shortness of breath, sore throat, chest pain, headache, or confusion. ${ }^{16}$

\section{Transmission}

It was initially proposed that the main transmission route of SARSCoV-2 was human-to-human transmission via respiratory droplets or close contact. ${ }^{17}$ The science behind maintaining social distance is that the larger particles from cough droplets are transmitted for $<1 \mathrm{~m}$ and do not remain suspended in air. ${ }^{18}$ However, according to the recent WHO report, SARS-CoV-2 can spread via oral and nasal droplets and it can float in the air in the form of aerosol and cause infection in healthy individual. ${ }^{17}$ It has recently been alerted by the American Academy of Ophthalmology that SARS-CoV-2 can cause mild follicular conjunctivitis and possibly be transmitted by aerosol when in contact with conjunctiva. ${ }^{19}$ Moreover, conjunctivitis may be the first presenting symptom of COVID-19. ${ }^{20}$

When the aerosols in the air settle down, they might potentially contaminate the inanimate objects forming fomites, which might act as possible routes to pass pathogens between people. This leaves dental professionals in potentially high-risk situations due to aerosol-generating treatment modalities. The presence of ACE2 receptors which are the binding sites of SARS-CoV- $2^{15}$ on the mucosa of tongue in oral cavity, frequent exposure to saliva, blood, and, most importantly, operatory position of the dentists while evaluating and treating the patients brings them within the range of aerosol and droplet transmission. Occupational Safety and Health Act has categorized dentistry as a very high exposure risk job with high potential for exposure to COVID-19 during specific aerosol-generating procedures. $^{21}$

Large number of droplets, aerosols, and splatter could be produced by the usage of instruments, such as dental handpieces, ultrasonic scalers, air polishers, and air abrasion units, during various dental procedures. These instruments remove material from the operative site that has the potential to get aerosolized by the action of high-speed rotary instruments, ultrasonic vibrations, or the three-way syringe that has the combined action of water sprays and compressed air. ${ }^{22}$

Aerosol contaminated with microbes has the potential to enter the respiratory tract through the leaks in the mask. ${ }^{23}$ Dental operatory may be contaminated with aerosol for 30 minutes after the dental procedure. ${ }^{24}$ Immediate removal of protective barrier after the dental procedure increases the chances of contact with contaminated aerosol. Therefore, to prevent the spread of COVID19 , the standard protective measures are not effective enough and it warrants additional infection control considerations. Since, SARS-CoV-2 has very high transmissibility, and if there is a lack of stringent disease control it may jeopardize the first-line healthcare workers. ${ }^{16,25}$

On January 23, 2020, Department of Preventive Dentistry in Wuhan University Dental Hospital reported its first case of a dentist being tested positive for COVID-19. Later, the transmission of disease to eight other healthcare workers was reported. ${ }^{25}$ On April 8, 2020, the Centers for Disease Control and Prevention (CDC) advocated to postpone elective dental procedures, surgeries, and non-urgent dental visits and to prioritize urgent and emergency visits and procedures until further notification.

The face of dentistry is going to change, when the mandates are lifted and the dentists reopen their practices. While microbial threats continue to emerge, reemerge, and persist, ${ }^{26}$ dental community has to react swiftly by adopting the standard precautions. Bearing in mind that the new SARS-CoV-2 is contagious with high rate of transmissibility and is commonly spread by asymptomatic and presymptomatic transmission, ${ }^{19}$ it is prudent to review the preexisting infection control procedures and implement the new guidelines laid by WHO and CDC to protect the dentists, the dental team, and the patients.

Specifically, the branches of dentistry that deal with geriatric patients need to be more vigilant and completely prepared because, elderly people with debilitating diseases, such as diabetes, hypertension, cardiovascular disease, and cerebrovascular disease, are more susceptible to severe illness and the mortality of elderly patients is higher. ${ }^{27}$

Prosthodontics is the field of dentistry that deals with fixed dental/maxillofacial prosthesis, removable dental/maxillofacial prosthesis, and implantology, thereby restoring the oral function and esthetics. Prosthodontists deal majorly with the geriatric patients and help them by restoring the oral function. From a prosthodontist point of view, there are chances of transmission through aerosol from the patient to the operator and the people in operatory area during the dental procedure (Nosocomial Infection in Dental Settings). Transmission to lab technicians can occur through impression material, bite registration materials, verification jig, trial dentures, and so on. In addition, care must be taken by the geriatric patients with their removable prosthesis that could be a potential source of further spread.

At present, when there is no treatment or vaccine available to treat COVID-19, controlling the source of infection and using the prevention/control measure to lower the risk of transmission is the best approach. ${ }^{16}$ This study is an attempt to understand the preventive measures against COVID-19. And it also aims at preventing the further spread through proper handling of dental material in the dental setup.

\section{Precautions to be Taken by the Prosthodontists during Different Procedures against SARS-CoV-2}

\section{Personal Protective Equipment (PPE) for the Operator}

Gown, mask or respirator, goggles or face shield, and gloves should be worn and removed according to the PPE protocol given by the CDC. ${ }^{28}$ All PPE should be removed before exiting the patient room except the respirator, which should be removed after leaving the patient room and closing the door. Hands should be washed with soap, or an alcohol-based hand sanitizer should be used immediately after removing all PPE. ${ }^{28}$

Healthcare workers and their assistants working within 6 feet of patients known to be, or suspected of being, infected with SARSCoV-2 and those performing aerosol-generating procedures need to use respirators:

- Using N95 filtering facepiece respirators or better must be prioritized.

- In non-availability of N95 filtering facepiece respirators, consider using other respirators that provide greater protection and improve worker comfort. Other acceptable types of respirators include an R/P95, N/R/P99, or N/R/P100 filtering facepiece respirator.

- Usage of powered air-purifying respirators (PAPRs) or supplied air respirators (SARs) should be considered; these are more 
protective than filtering facepiece respirators, for any work operations or procedures likely to generate aerosols.

- On top of a respirator, a face shield may also be worn to prevent bulk contamination of the respirator. ${ }^{21}$

\section{Preparation of the Patient}

Oral cavity being the potential source of SARS-CoV-2, mouth rinse should be used before the start of any procedure. Studies in the past have shown high susceptibility of SARS-CoV and MERSCoV to povidone mouth rinse. ${ }^{29}$ Hence, $0.2 \%$ povidone-iodine as preprocedural mouth rinse might reduce the load of CoVs in saliva. ${ }^{2,30,31}$ Alternatively, $0.5 \%$ to $1 \%$ hydrogen peroxide mouth rinse can be used, because it has non-specific viricidal activity against CoVs. ${ }^{31}$

\section{Rubber Dam Isolation}

When high-speed handpieces and dental ultrasonic devices are used, the production of saliva and/or blood contaminated aerosol or splatter can be reduced significantly using a rubber dam isolation. Extra high-volume suction for aerosol and splatter should be used when rubber dam is applied during the procedures along with regular suction. Implementation of four-handed dentistry is necessary in such cases. ${ }^{26,32}$ A spoon excavator and a hand scaler are recommended for caries removal and periodontal scaling to minimize the generation of aerosol when rubber dam isolation is not possible. ${ }^{2}$

\section{Disinfection of the Impression Materials}

Impressions can be easily contaminated by patient's saliva and blood; hence it is the source of cross-contamination among the dentist, the patient, and the dental technician. ${ }^{33}$ Impressions can also be a source of SARS-CoV-2 spread, since SARS-CoV-2 can remain viable in saliva and survive up to 3 days on inanimate surfaces at room temperature, with a greater preference for humid conditions. ${ }^{34}$ Corona virus is inactivated by steam and heat and also susceptible to many active ingredients, such as sodium hypochlorite $(0.1 \%-0.5 \%), 70 \%$ ethyl alcohol, povidone-iodine, chloroxylenol (0.24\%), $50 \%$ isopropanol, $0.05 \%$ benzalkonium chloride, $1 \%$ cresol soap, or hydrogen peroxide. ${ }^{16}$ Sodium hypochlorite $0.1 \%$ and UV irradiation have a stronger viricidal effect by completely inhibiting the viral replication and by damaging the viral within 2 minutes of exposition. Particularly, sodium hypochlorite $0.1 \%$ within 1 minute of contact with SARS-CoV prevents it replication. Also, the genome integrity of virus is lost. ${ }^{35}$

- Alginate: Povidone-iodine rapidly inactivates the SARS-CoV and the MERS-CoV. ${ }^{29}$ As a precautionary measure, povidoneiodine disinfectant solution can also be used for disinfecting the alginate impressions. A study by Dulaimi and Al-Wahab stated that povidone-iodine disinfectant solution did not affect the stability of alginate and surface detail reproduction of the resultant casts. ${ }^{36} \mathrm{~A}$ self-disinfecting irreversible hydrocolloid impression material mixed with povidone-iodine powder can also be used. Modified alginate impression material with 15 weight $\%$ povidone-iodine is the recommended concentration to produce the self-disinfecting impression material with less deteriorating effect on alginate. ${ }^{37}$ Sodium hypochlorite $0.525 \%$ could disinfect alginate most effectively at $\mathrm{pH} 10$ or lower. ${ }^{38}$

- Elastomeric impression: Immersion of silicone impression in $0.5 \%$ sodium hypochlorite for 5 to 10 minutes is enough to be viricidal ${ }^{35}$ and to inhibit bacterial growth without losing the dimensional stability. ${ }^{39}$ A $3 \%$ hydrogen peroxide without significant changes in three-dimensional silicone dental impressions showed high antimicrobial efficiency. Hydrogen peroxide which is less explored could also be a valuable alternative for silicone impression disinfection. ${ }^{40}$ Polysulfide and polyether can be disinfected using $0.5 \%$ sodium hypochlorite or povidone-iodine. ${ }^{41,42}$

- Zinc oxide eugenol: Zinc oxide eugenol impression should be immersed in $0.5 \%$ sodium hypochlorite for 10 minutes. ${ }^{43,44}$

\section{Impression Trays}

According to the studies, the SARS-CoV-2 was infectious for approximately 48 hours and 72 hours on stainless steel and plastic, respectively. ${ }^{34,45}$ Hence, before and after making the impressions, the stainless steel and plastic impression trays should be sterilized in an airtight sterilization pouch. Acrylic custom resin impression trays should be disinfected in either 1:2 iodophor or 1:10 sodium hypochlorite. ${ }^{46}$

\section{Disinfection of Trial Dentures, Occlusal Rims, Cast, and Bite Registration Material}

The trial denture and wax occlusal rims can be disinfected by spraying the iodophor, i.e., povidone-iodine solution on it. After disinfecting the trial dentures and wax rims, they should be stored in an airtight pouch and should be again rinsed under water. Disinfectants used for impression materials can be used for bite registrations made of various materials, such as zinc oxide eugenol (ZOE) or elastomers. A 1:10 dilution of sodium hypochlorite or an iodophor can be used for disinfection of stone cast by spraying until wet or immersing in the disinfectant. Cast which is to be disinfected should be fully set. ${ }^{46}$

\section{Disinfection of Shade Guide}

There is no preferred disinfectant for shade tab which can disinfect the shade tab without changing its color. Tap water and steam can be used to disinfect the shade tab. ${ }^{47}$

\section{Dental Burs and Handpiece}

Dental bur, the smallest thing in the operatory, can be the biggest cause in spread of SARS-CoV-2 due to cross infection. Dry heat is the preferred method for sterilization of burs as stated by council on dental materials, but it produces little rusting or dulling of burs. ${ }^{48}$ Autoclaving can destroy all microorganisms, and it is the best method to decontaminate dental burs and handpiece. ${ }^{49,50}$ In the amidst of COVID-19, using a new bur for every patient should be considered.

\section{Precautions in the Dental Operatory}

Pre-screening test for SARS-CoV-2 should be performed for every patient ${ }^{51}$ and the dentist should take a history of symptoms, such as fever, dry cough, sore throat, or shortness of breath. It is a fact that patient may be asymptomatic but SARS-CoV-2 positive, hence all patients should be assumed to be infective. ${ }^{52}$ Waste management must follow well-defined rules. ${ }^{53}$

As aerosol-generating procedures have been associated with an increased risk of transmission of $\mathrm{CoVs}^{54,55}$ the following guidelines should be followed while performing aerosol-generating procedures:

- Operatory should be adequately ventilated-i.e., natural ventilation with air flow of at least $160 \mathrm{~L} / \mathrm{s}$ per patient or in negative-pressure rooms with at least 12 air changes per hour. ${ }^{56}$ 
- Eye protection or face shield should be used..$^{55}$

- A clean, sterile, long-sleeved gown and gloves should be used. If gowns are not fluid-resistant, a waterproof apron must be used by the operator for procedures which are expected to create high volumes of fluid that might penetrate the gown. ${ }^{55,57}$

- Limiting the number of persons present in the operatory to minimum. ${ }^{55}$

\section{Disinfection of Dental Chair Water Supply and Suction Tubing}

Human coronavirus ( $\mathrm{HCoV}$ ) is not typically waterborne, and hence water consideration is not the first priority while managing its spread. Since the virus is newly discovered, there is no certain information about the survival of virus in water and wastewater. ${ }^{58}$ Nasal secretions and saliva are found in wastewater potentiating the entry of SARS-CoV-2 into the wastewater system. Based on this, there are chances that SARS-CoV-2 may be present in wastewater where COVID-19 infections are already present. ${ }^{58}$ The SARS-CoV-2 may remain viable in the suction pipe, the spittoon, and the tubing of dental chair. The CoVs having a lipid envelope are typically more sensitive to oxidant disinfectants. Severe acute respiratory syndrome coronavirus was found to be very sensitive to chlorine and chlorine dioxide disinfection, which is closely related to SARSCoV-2. ${ }^{59}$ Hence, adding such disinfectants to the water supply of the dental chair may help to reduce the spread of COVID. A thorough suction of water containing the above-mentioned disinfectant should be performed to disinfect the suction pipes.

\section{Instructions for Geriatric Patients Wearing Removable Prosthesis Amidst SARS-CoV-2}

Special care must be taken by the patient to disinfect the removable prosthesis, since the prosthesis is in constant contact with the saliva. Severe acute respiratory syndrome coronavirus- 2 can survive up to 3 days on inanimate surfaces at room temperature, ${ }^{34}$ but there is no literature about survival of SARS-CoV-2 on the resin surface. Disinfecting the removable denture should be a concern due to its potential to be a source of vehicle for the spread of SARS-CoV-2.

Cast partial denture with chrome cobalt alloy should be immersed in iodophors or 1:10 hypochlorite for 10 minutes. lodophors or chlorine compounds are preferred for heat cured denture base resin and all acrylic appliances. ${ }^{46,60}$ Before disinfection, prostheses or appliances worn by the patients should be cleaned thoroughly with a soft brush in soap water. Storage of prostheses should never be done in a disinfectant before insertion. After disinfection, the prostheses should be cleaned scrupulously with water and stored in a diluted mouthwash until inserted. ${ }^{46}$

\section{Instructions for Dental Technicians for Proper Communication Regarding Disinfection}

Effective communication and coordination are the important factors between the prosthodontist and the laboratory. This will help in confirmation of appropriate disinfection procedure performed in clinic, thereby preventing distortion of dental material because of over exposure and also avoiding the chance of unnecessary double usage of disinfectant.
The prescription sent to the laboratory should mention the disinfection procedure in brief (e.g., type of disinfectant and exposure time). Communication is the key between the laboratory and the prosthodontist to determine who is responsible for the final disinfection process. In the absence of communication, the received work from the dentist should be disinfected by the laboratory before handling it. Contaminated prostheses or impressions can be transported to the laboratory, so a separate receiving and disinfecting area should be established in the laboratory.

Personal protective equipment should be worn either in the office or in the laboratory. Items which do not come in direct contact with the patient, such as articulator, lathe, or acrylic trimmer; these cannot be heat sterilized, so it should be cleaned and disinfected according to the manufacturer's instructions. ${ }^{61}$

\section{Conclusion}

International community has been challenged on multiple levels by highly transmissible viral diseases for the past two decades and SARS-CoV-2 will not be the very last pathogen to challenge the healthcare profession. Therefore, it is high time to discover the new guidelines for our dental practice in such menacing outbreak of pathogens like COVID-19. People should consider aerobiological engineering principle to design new clinics and redesign the existing ones. High efficiency particulate air, an extra oral evacuation device, can be effectively used to control the generated aerosol. ${ }^{62}$ We need to be one step ahead in understanding both the virus and the disease, especially the asymptomatic phase of COVID-19. To overcome this undetectable phase, new disinfecting procedures should be adopted to terminate the virus. Due to the absence of vaccine for SARS-CoV-2, PPE protocol given by the CDC should be followed strictly. Amidst and after the pandemic of COVID-19, it is necessary for the prosthodontist to safeguard himself, the dental auxiliaries, the dental technicians, and the patients from the risk of cross infection by taking proper precautionary measures.

\section{References}

1. Ge ZY, Yang LM, Xia JJ, et al. Possible aerosol transmission of COVID-19 and special precautions in dentistry. J Zhejiang Univ-SCI B 2020(5):1-8. DOI: 10.1631/jzus.B2010010.

2. Peng $X, X u X$, Li Y, et al. Transmission routes of SARS-CoV-2 and controls in dental practice. Int J Oral Sci 2020;12(1):1-6. DOI: 10.1038/ s41368-020-0075-9.

3. Zhou P, Yang XL, Wang XG, et al. A pneumonia outbreak associated with a new coronavirus of probable bat origin. Nature 2020;579(7798):270-273. DOI: 10.1038/s41586-020-2012-7.

4. Zhu N, Zhang D, Wang W, et al. A novel coronavirus from patients with pneumonia in China, 2019. New England J Med 2020.

5. Naming the coronavirus disease (COVID-19) and the virus that causes it. Cited from https://www.who.int/emergencies/diseases/novelcoronavirus-2019/technical-guidance/naming-the-coronavirusdisease-(covid-2019)-and-the-virus-that-causes-it.

6. Chen J. Pathogenicity and transmissibility of SARS-CoV-2-a quick overview and comparison with other emerging viruses. Microbes Infect 2020.

7. Cui J, Li F, Shi ZL. Origin and evolution of pathogenic coronaviruses. Nat Rev Microbiol 2019;17(3):181-192. DOI: 10.1038/s41579-018-01189.

8. Bárcena M, Oostergetel GT, Bartelink W, et al. Cryo-electron tomography of mouse hepatitis virus: insights into the structure of the coronavirion. Proceed Nation Acad Sci 2009;106(2):582-587. DOI: 10.1073/pnas.0805270106. 
9. Neuman BW, Adair BD, Yoshioka C, et al. Supramolecular architecture of severe acute respiratory syndrome coronavirus revealed by electron cryomicroscopy. J Virol 2006;80(16):7918-7928. DOI: 10.1128/ JVI.00645-06.

10. Fehr AR, Perlman S. Coronaviruses: an overview of their replication and pathogenesis. InCoronaviruses. . New York, NY: Humana Press; 2015. pp. 1-23.

11. Chan JF, Kok KH, Zhu Z, et al. Characterization of the 2019 novel human-pathogenic coronavirus isolated from a patient with atypical pneumonia after visiting Wuhan. Emerg Micro Infect 2020;9(1): 221-236. DOI: 10.1080/22221751.2020.1719902.

12. Zhou $P$, Yang $X L$, Wang $X G$, et al. Discovery of a novel coronavirus associated with the recent pneumonia outbreak in humans and its potential bat origin. BioRxiv 2020.

13. Zheng J. SARS-CoV-2: an emerging coronavirus that causes a global threat. Int J Biol Sci 2020;16(10):1678. DOI: 10.7150/ijbs.45053.

14. Hamming I, Timens W, Bulthuis ML, et al. Tissue distribution of ACE2 protein, the functional receptor for SARS coronavirus. A first step in understanding SARS pathogenesis. J Patholog: J Patholog Soc Great Br Ireland 2004;203(2):631-637. DOI: 10.1002/path.1570.

15. Xu H, Zhong $L$, Deng J, et al. High expression of ACE2 receptor of SARS-CoV-2 on the epithelial cells of oral mucosa. Int J Oral Sci 2020;12(1):1-5. DOI: 10.1038/s41368-017-0006-6.

16. Wu YC, Chen CS, Chan YJ. The outbreak of COVID-19: an overview. J Chin Med Associat 2020;83(3):217-220. DOI: 10.1097/ JCMA.0000000000000270.

17. Kolifarhood G, Aghaali M, Saadati HM, et al. Epidemiological and clinical aspects of COVID-19; a narrative review. Archi Acad Emerg Med 2020;8(1).

18. Seto WH. Airborne transmission and precautions: facts and myths. J Hospital Infect 2015;89(4):225-228. DOI: 10.1016/j.jhin.2014. 11.005 .

19. Important coronavirus updates for ophthalmologist. Cited from https://www.aao.org/headline/alert-important-coronavirus-context.

20. Lu CW, Liu XF, Jia ZF. 2019-nCoV transmission through the ocular surface must not be ignored. Lancet (London, England) 2020;395(10224):e39. DOI: 10.1016/S0140-6736(20)30313-5.

21. Guidance on Preparing Workplaces for COVID-19. Cited from https:// www.osha.gov/Publications/OSHA3990.pdf.

22. Harrel SK, Molinari J. Aerosols and splatter in dentistry: a brief review of the literature and infection control implications. J Am Dent Associat 2004;135(4):429-437. DOI: 10.14219/jada.archive.2004.0207.

23. Pippin DJ, Verderame RA, Weber KK. Efficacy of face masks in preventing inhalation of airborne contaminants. J Oral Maxillofac Surg 1987;45(4):319-323. DOI: 10.1016/0278-2391(87)90352-1.

24. Hinds WC. Aerosol technology: properties, behavior, and measurement of airborne particles. John Wiley \& Sons 1999.

25. Meng L, Hua F, Bian Z. Coronavirus disease 2019 (COVID-19): emerging and future challenges for dental and oral medicine. J Dent Res 2020(5):0022034520914246. DOI: 10.1177/0022034520914246.

26. Samaranayake LP, Peiris $M$. Severe acute respiratory syndrome and dentistry: a retrospective view. J Am Dent Associat 2004;135(9):12921302. DOI: 10.14219/jada.archive.2004.0405.

27. Liu K, Chen Y, Lin R, et al. Clinical features of COVID-19 in elderly patients: a comparison with young and middle-aged patients. J Infect 2020;80(6):e14-e18.

28. Sequence For Putting Onpersonal Protective Equipment (PPE). Cited from https://www.cdc.gov/hai/pdfs/ppe/ppe-sequence.pdf.

29. Eggers $M$, Koburger-Janssen $T$, Eickmann $M$, et al. In vitro bactericidal and virucidal efficacy of povidone-iodine gargle/mouthwash against respiratory and oral tract pathogens. Infect Dis Ther 2018;7(2): 249-259. DOI: 10.1007/s40121-018-0200-7.

30. Kariwa H, Fujii N, Takashima I. Inactivation of SARS coronavirus by means of povidone-iodine, physical conditions, and chemical reagents. Japan J Veterin Res 2004;52(3):105-112.

31. Ather A, Patel B, Ruparel NB, et al. Coronavirus disease 19 (COVID-19): implications for clinical dental care. J Endod 2020(5). DOI: 10.1016/ j.joen.2020.03.008.
32. Samaranayake LP, Reid J, Evans $D$, The efficacy of rubber dam isolation in reducing atmospheric bacterial contamination.

33. Flanagan DA, Palenik CJ, Setcos JC, et al. Antimicrobial activities of dental impression materials. Dent Mater 1998;14(6):399-404. DOI: 10.1016/s0300-5712(99)00013-5.

34. van Doremalen N, Bushmaker T, Morris DH, et al. Aerosol and surface stability of SARS-CoV-2 as compared with SARS-CoV-1. New England J Med 2020;382(16):1564-1567.

35. Ansaldi F, Banfi F, Morelli P, et al. SARS CoV, influenza A and syncitial respiratory virus resistance against common disinfectants and ultraviolet irradiation. J Prev Med Hyg 2004;45(1-2):5-8.

36. Dulaimi SF, Al-Wahab ZN. The effect of disinfectants on the surface quality of irreversible hydrocolloid impression material and gypsum cast. Nursing National Iraqi Specility 2012;25(1):95-100.

37. Ismail HA, Asfour $H$, Shikho SA. A self-disinfecting irreversible hydrocolloid impression material mixed with povidone iodine powder. Eur J Dent 2016;10(04):507-511. DOI: 10.4103/13057456.195172.

38. Rweyendela IH, Patel M, Owen CP. Disinfection of irreversible hydrocolloid impression material with chlorinated compounds: scientific. Sou Afr Dent J 2009;64(5):208-212.

39. Bustos J, Herrera R, González U, et al. Effect of immersion disinfection with $0.5 \%$ sodium hypochlorite and $2 \%$ glutaraldehyde on alginate and silicone: microbiology and SEM study. Int J Odontostomat 2010;4(2):169-177. DOI: 10.4067/S0718-381X2010000200011.

40. Azevedo MJ, Correia I, Portela A, et al. A simple and effective method for addition silicone impression disinfection. J Adv Prosthodont 2019;11(3):155-161. DOI: 10.4047/jap.2019.11.3.155.

41. Herrera SP, Merchant VA. Dimensional stability of dental impressions after immersion disinfection. J Am Dent Associat 1986;113(3):419-422. DOI: 10.14219/jada.archive.1986.0214.

42. Khan MW. An overview of dental impression disinfection techniques-A literature review. JPDA 2018;27(04):208. DOI: 10.1016/ j.jsps.2018.11.013.

43. Amin WM, Al-Ali MH, Al Tarawneh SK, et al. The effects of disinfectants on dimensional accuracy and surface quality of impression materials and gypsum casts. J Clin Med Res 2009;1(2):81. DOI: 10.4021/ jocmr2009.04.1235.

44. Sukhija U, Rathee M, Kukreja N, et al. Efficacy of various disinfectants on dental impression materials. Internet J Dent Sci 2009;9(1):1-6.

45. Eykelbosh A, COVID-19 Precautions for Multi-unit Residential Buildings. BC Centre for Disease Control, National Collaborating Centre for Environmental Health. 2020.

46. Jain S, Yadav B, Phogat $S$, et al. Disinfection in Prosthodontics int. J Dent Health Sci 2014;1:779-787.

47. Alamri MD. The effect of disinfecting solutions on the color of porcelain shade guides. Egypt Dent J 2008;54(2):1057-1066.

48. Schutt RW, Starsiak WJ. Glass bead sterilisation of surgical dental burs. Int J Oral Maxillofac Surg 1990;19(4):250-251. DOI: 10.1016/ s0901-5027(05)80404-7.

49. Sajjanshetty S, Hugar D, Hugar S, et al. Decontamination methods used for dental burs-a comparative study. J Clin Diagnos Res 2014;8(6):ZC39. DOI: 10.7860/JCDR/2014/9314.4488.

50. Harvey $\mathrm{W}$, Lemay $\mathrm{CH}$, Shuttleworth $\mathrm{CW}$. The sterilization of dental handpieces. Proc R Soc Med 1947;40(9):507-511. DOI: 10.1177/003591574704000922.

51. Zimmermann M, Nkenke E. Approaches to the management of patients in oral and maxillofacial surgery during COVID-19 pandemic. J Cranio-Maxillofac Surg 2020(5). DOI: 10.1016/j.jcms.2020.03.011.

52. Rothe C, Schunk M, Sothmann P, et al. Transmission of SARS-CoV-2 infection from an asymptomatic contact in Germany. New England J Med 2020;382(10):970-971. DOI: 10.1056/NEJMc2001468.

53. World Health Organization. Safe management of wastes from healthcare activities: a summary. World Health Organization; 2017.

54. Tran K, Cimon K, Severn M, et al. Aerosol generating procedures and risk of transmission of acute respiratory infections to healthcare workers: a systematic review. PLoS ONE 2012;7(4). DOI: 10.1371/ journal.pone.0035797. 
55. World Health Organization, Infection prevention and control during health care when COVID-19 is suspected: interim guidance, 19 March 2020. World Health Organization; 2020.

56. Chartier Y, Pessoa-Silva CL. Natural ventilation for infection control in health-care settings. World Health Organization, 2009.

57. World Health Organization. Infection prevention and control of epidemic-and pandemic-prone acute respiratory infections in health care. World Health Organization; 2014.

58. SARS-CoV-2 - water and sanitation. Adelaide: Water Research Australia;; 2020.
59. Wang XW, Li JS, Jin M, et al. Study on the resistance of severe acute respiratory syndrome-associated coronavirus. J Virol Methods 2005;126(1-2):171-177. DOI: 10.1016/j.jviromet.2005.02.005.

60. Affairs AC, Practice AC. Infection control recommendations for the dental office and the dental laboratory. J Am Dent Associat 1996;127(5):672-680. DOI: 10.14219/jada.archive.1996.0280.

61. Kohn WG, Collins AS, Cleveland JL, et al., Guidelines for infection control in dental health-care settings-2003.

62. Sukumaran A, Patil S. The MERS-CoV outbreak: challenges facing the dental profession. J Contemp Dent Pract 2014;15(2):i. DOI: 10.5005/ jcdp-15-2-i. 